\title{
Aberrant Maxillary Sinus Anatomy in a Cystic Fibrosis Patient
}

\author{
Timothy Baerg ${ }^{1}$, Jennifer F Ha ${ }^{* 2,3,4}$, Sheena Bahroloomi and David J Brown ${ }^{1}$ \\ ${ }^{1}$ University of Michigan Medical School, USA \\ ${ }^{2}$ Department of Otolaryngology Head \& Neck Surgery, University of Michigan Health System, USA \\ ${ }^{3}$ Department of Surgery, University of Western Australia, Australia \\ ${ }^{4}$ St John of God Hospital (Murdoch), Australia
}

Submission: October 23, 2017; Published: November 10, 2017

*Corresponding author: Jennifer Ha, Wexford Medical Center Suite, 17/18, Level 1, 3 Barry Marshall Parade, Murdoch 6150, Australia,

Tel: +61863326868; Fax: +6186332 6800; E-mail: drjennha@yahoo.com.au

Keywords: Cystic Fibrosis; Chronic Rhinosinusitis; Aberrant Maxillary Sinus; Maxillary Antrostomy

\section{Opinion}

Cystic fibrosis (CF), a disease characterized by a heterozygous mutation in the Cystic Fibrosis Transmembrane Regulator (CFTR) gene, often involves the lungs, gastrointestinal tract, and upper respiratory tract. CF patients have an increased likelihood of developing chronic rhinosinusitis (CRS), especially those with a homozygous $\triangle F 508$ mutation [1]. CRS may result in decreased pneumatisation of the frontal and sphenoid sinuses, manifesting in a decreased size or a complete absence of the sinus [1,2]. Independent of CRS, both homozygous and heterozygous mutations have been found to impair sinus development, leading to decreased anatomical volumes; indicating that paranasal size is correlated with CFTR function [2].

While CRS has been linked to abnormal sinus anatomy, CRS in the setting of CF has been linked to this phenomenon in a different way [3]. Lateral nasal wall medialisation, bilateral uncinated process demineralization, and middle meatus displacement have been described in CF with CRS, but these phenotypes are less commonly seen in patients with CRS only. These findings suggest that there is an elevated sinus pressure in CRS in the setting of CF. Moreover, erosion secondary to osteitis or nasal polyp and mucus mediated pressure can lead to the formation of pseudomucoceles [4]. CRS secondary to CF has been reported to occur in $63 \%$ of adult CF patients [1]. Due to prevalence and potential downstream complications that may occur, research characterizing the potential effects of aberrant sinus anatomy in the setting of CRS and CF has important clinical implications. We describe an unusual sinus anatomy secondary to CRS in a patient with $\mathrm{CF}$.
Case Report

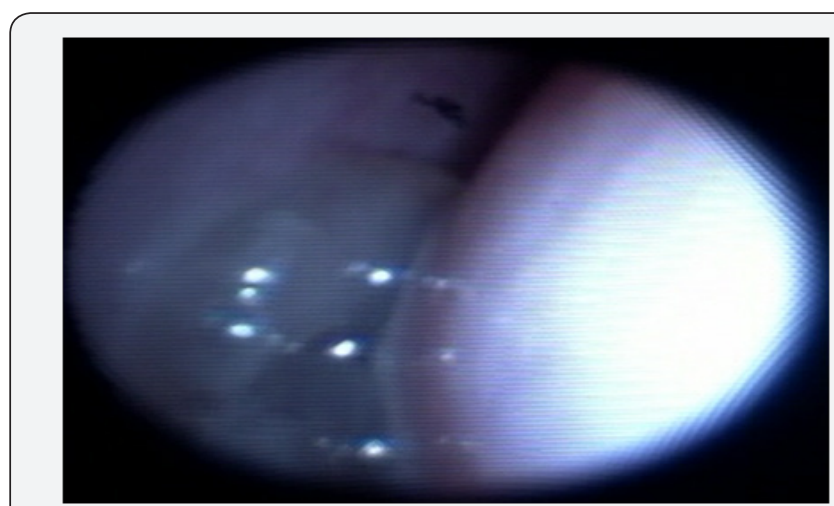

Figure 1: Right sided nasal polyposis.

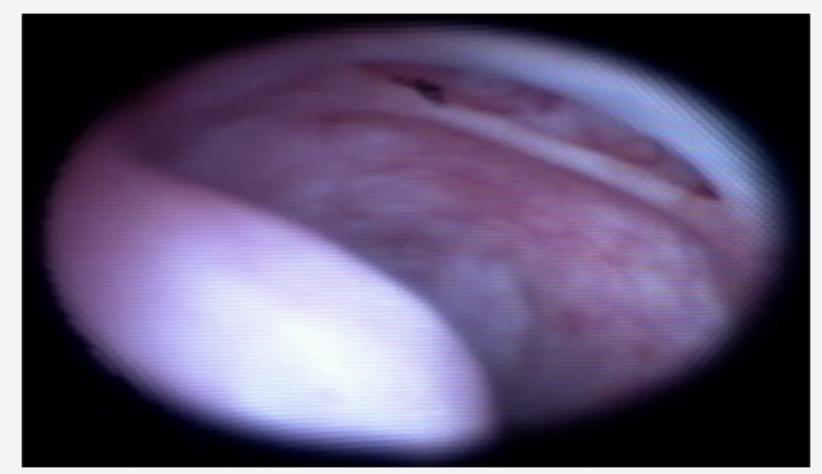

Figure 2: Left sided inferior meastomy. 


\section{Global Journal of Otolaryngology}

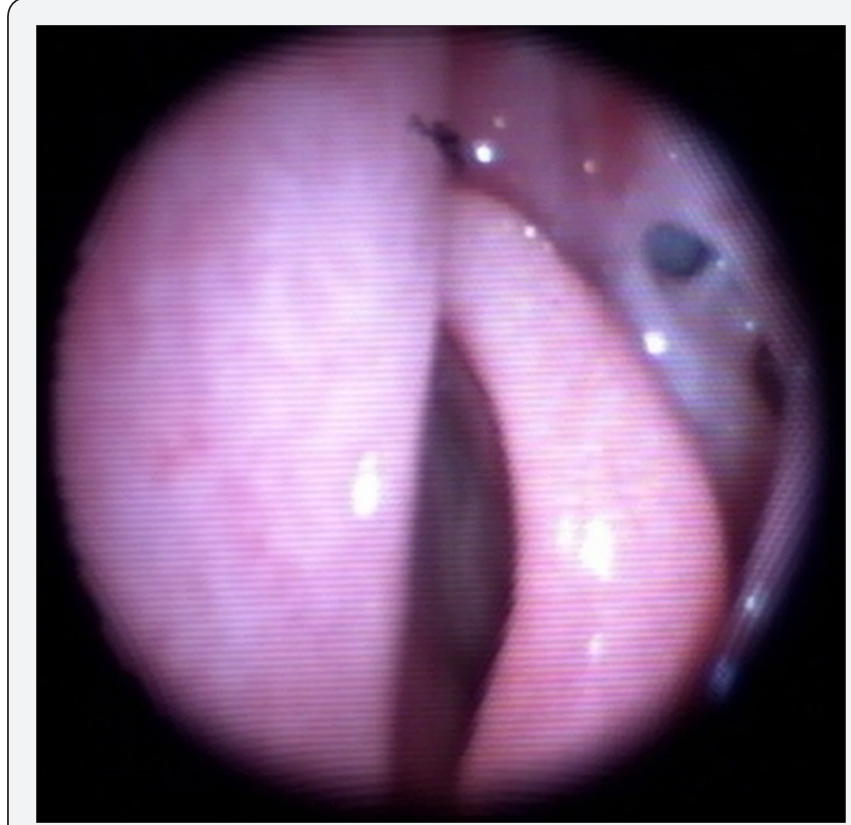

Figure 3: Left sided maxillary antrum.

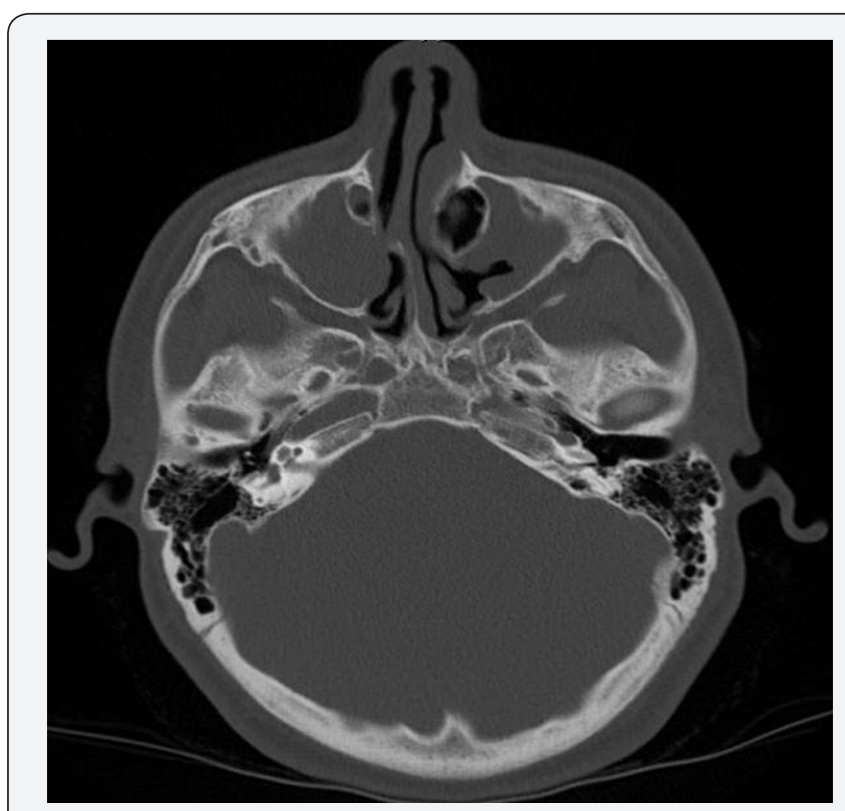

Figure 4: Apparent left maxillary antrostomy that was seen clinically

A 16-year-old boy with a history of right nasal obstructions and purulent rhinorrhea on a background of left nasal septal deviation, and cystic fibrosis (CF) presented to our pediatric otorhinolaryngologyclinic in August 2015. The flexible nasendoscopy, confirmed large right-sided nasal polyposis (Figure 1), an apparent left inferior meatus window (Figure 2) and apparent maxillary antrostomy (Figure 3). However, he had no prior history of any sinonasal surgery. The computed tomography of his paranasal sinus confirmed the aberrant anatomy in the setting of his chronic rhinosinusitis (CRS) (Figure 4).

\section{Discussion}

Approximately 15 million Americans have at least one CFTR mutation, and one third of the mare expected to develop CRS [2]. While various studies have outlined that sinus size may decrease in the setting of CRS in CF, our patient's findings have yet to be extensively explored The aberrant anatomy in our patient may have developed as a result of the chronicity of the inflammatory process and bony erosion due to an expansile maxillary mucocele. The treatment of patients like ours is often conservative with systemic antibiotics, intranasal corticosteroids and nasal irrigations. Surgical treatment is reserved for large nasal polyposis when they significantly interferes with the patient's quality of life.

The inferior meatus antrostomy procedure has been used to drain the maxillary sinus, but a maxillary antrostomy of the middle meatus is currently the standard of care. This procedure is effective for treating medically resistant CRS. However, in the setting of CRS, anterior bone displacement may occur, and ostial thickening may increase the challenge of surgery [5]. Since, however, the anterior portion of the sinus must be patent for effective mucociliary clearance, severe obstruction may be ablated through cutting instruments or cured powered microdebriders [5]. Complications of this are secondary to the stripping of the mucosa, leaving bone exposure on the posterior aspect of the lacrimnal duct. An image guidance system should be used to aid in antrostomy.

\section{Conclusion}

To our knowledge, this is a first report of an aberrant inferior meatus ostium in the setting of CF with CRS. Since CRS is common in CF patients, it is important to be aware of anatomical aberrations for safe and successful surgical therapy. Through maxillary antrostomy, patients with this condition may avoid the downstream complications of CRS intervention.

\section{References}

1. Berkhout M (2014) Sinonasal manifestations of cystic fibrosis: A correlation between genotype and phenotype? Journal of Cystic Fibrosis 13(4): 442-448.

2. Calton J, Koripella P, Willis A, Le C, Chiu A, et al (2016) Paranasal sinus size is decreased in CFTR heterozygotes with chronic rhinosinusitis. International Forum of Allergy \& Rhinology 7(3): 256-260.

3. Kang SH, Piltcher OB, Dalcin PDTR (2014) Sinonasal alterations in computed tomography scans in cystic fibrosis: a literature review of observational studies. International Forum of Allergy \& Rhinology. 4(3): 223-231.

4. Kang S, Dalcin P, Piltcher O, Migliavacca R (2015) Chronic rhinosinusitis and nasal polyposis in cystic fibrosis: update on diagnosis and treatment. Jornal Brasileiro de Pneumologia 41(1): 65-76.

5. Kennedy DW, Adappa ND (2011) Endoscopic maxillary antrostomy: Not just a simple procedure. The Laryngoscope 121: 2142-2145. 
This work is licensed under Creative Commons Attribution 4.0 License

DOI: $10.19080 /$ GJ0.2017.11.555814

\section{Your next submission with Juniper Publishers} will reach you the below assets

- Quality Editorial service

- Swift Peer Review

- Reprints availability

- E-prints Service

- Manuscript Podcast for convenient understanding

- Global attainment for your research

- Manuscript accessibility in different formats

( Pdf, E-pub, Full Text, Audio)

- Unceasing customer service

Track the below URL for one-step submission https://juniperpublishers.com/online-submission.php 